\title{
Evaluation of Peroxidase in Herbal Medicines Based on an Electrochemical Sensor
}

\author{
Yinzi Yue ${ }^{1 \dagger}$, Lianlin $\mathrm{Su}^{2 \dagger}$, Min Hao ${ }^{3}$, Wenting $\mathrm{Li}^{1}, \mathrm{Li}_{\text {Zeng }}{ }^{*}$ and Shuai Yan ${ }^{4 *}$ \\ ${ }^{1}$ First Clinical Medical School, Nanjing University of Chinese Medicine, Nanjing, China, ${ }^{2}$ School of Pharmacy, Nanjing University of \\ Chinese Medicine, Nanjing, China, ${ }^{3}$ School of Pharmacy, Zhejiang Chinese Medicine University, Hangzhou, China, ${ }^{4}$ Department \\ of Anorectal, Suzhou TCM Hospital Affiliated to Nanjing University of Chinese Medicine, Suzhou, China
}

Peroxidases are species-specific. Differences in peroxidase can objectively reflect the genetics among species. The use of peroxidase to assist in species identification is relatively simple and effective. In this work, we proposed a graphene-modified electrode. This electrode can amplify the signal of electrocatalytic reduction of hydrogen peroxide.

\section{OPEN ACCESS}

Edited by:

Fatemeh Karimi,

Quchan University of Advanced

Technology, Iran

Reviewed by: Somaye Cheraghi,

Shahid Bahonar University of Kerman, Iran

Vahid Arabali,

Islamic Azad University Sar

Branch, Iran

*Correspondence:

Li Zeng

zengbingli@njucm.edu.cn

Shuai Yan

doctor_shuaiyan@njucm.edu.cn

tThese authors have contributed equally to this work

Specialty section: This article was submitted to Electrochemistry, a section of the journal Frontiers in Chemistry

Received: 14 May 2021 Accepted: 10 June 2021 Published: 23 June 2021

Citation:

Yue Y, Su L, Hao M, Li W, Zeng L and Yan S (2021) Evaluation of Peroxidase in Herbal Medicines Based on an Electrochemical Sensor.

Front. Chem. 9:709487. doi: 10.3389/fchem.2021.709487
Since peroxidase can catalyze the reduction of hydrogen peroxide, this signal can be used as an indicator to demonstrate the content of peroxidase in different plant tissues. Twelve herbal medicines were selected for our study. The results show that this electrochemicalbased detection technique was comparable to colorimetric method in terms of accuracy.

Keywords: peroxidase activity, herbal medicines, electrochemical evaluation, rapid detection, hydrogen peroxide

\section{INTRODUCTION}

The phenolics and enzymes in plant tissues are distributed in different locations in the cell. Enzymes cannot come into contact with phenolic substrates, so enzymatic browning does not occur (Paravisini and Peterson, 2019; Kizilgeci et al., 2020; Moon et al., 2020; Özkan, 2020). However, if damage or dehydration leads to the destruction of plant cell structure and changes the regionalized distribution of phenolics and enzymes, the contact between phenolic substances, enzymes and oxygen will cause enzymatic browning (Barpete et al., 2020). The presence of phenolic substrates, enzymes and oxygen is necessary for enzymatic browning to occur. Enzymes that cause enzymatic browning of plant include polyphenol oxidase, peroxidase, catalase, superoxide dismutase (Demir and Işı, 2020), phenylalanine aminotransferase, etc. Among them, peroxidase is the main oxidase that causes enzymatic browning in most plants (Ozbek et al., 2021; Tenish et al., 2021).

Peroxidase is an oxidase that uses hydrogen peroxide as an electron acceptor to catalyze substrates and is widely found in plants, animals, and microorganisms (Chen et al., 2020; Karimi-Maleh et al., 2021a; Lazzarotto et al., 2021). Most peroxidases contain heme cofactors and are mostly hemebinding proteins containing iron ions. There are also some peroxidases in which the iron of heme is replaced by copper, manganese, vanadium or selenium (Dong et al., 2020; Karimi-Maleh et al., 2021c). Therefore, according to the different cofactors, ferric heme peroxidases can be divided into two categories. The third type of structure is the chloride peroxidase and the cytochrome c peroxidase containing two hemoglobins (Fu et al., 2019; Li et al., 2020; Zhou et al., 2020). In addition, depending on the isoelectric point, it can be divided into acid peroxidase, neutral peroxidase and basic peroxidase. According to the binding state, it can be divided into soluble peroxidase, ion-bound peroxidase and covalent-bound peroxidase (Xu et al., 2020; Karimi-Maleh et al., 2021b).

The activity and number of peroxidases vary greatly in different tissues and organs, different growth, development periods, different physiological states and different varieties of plants. 

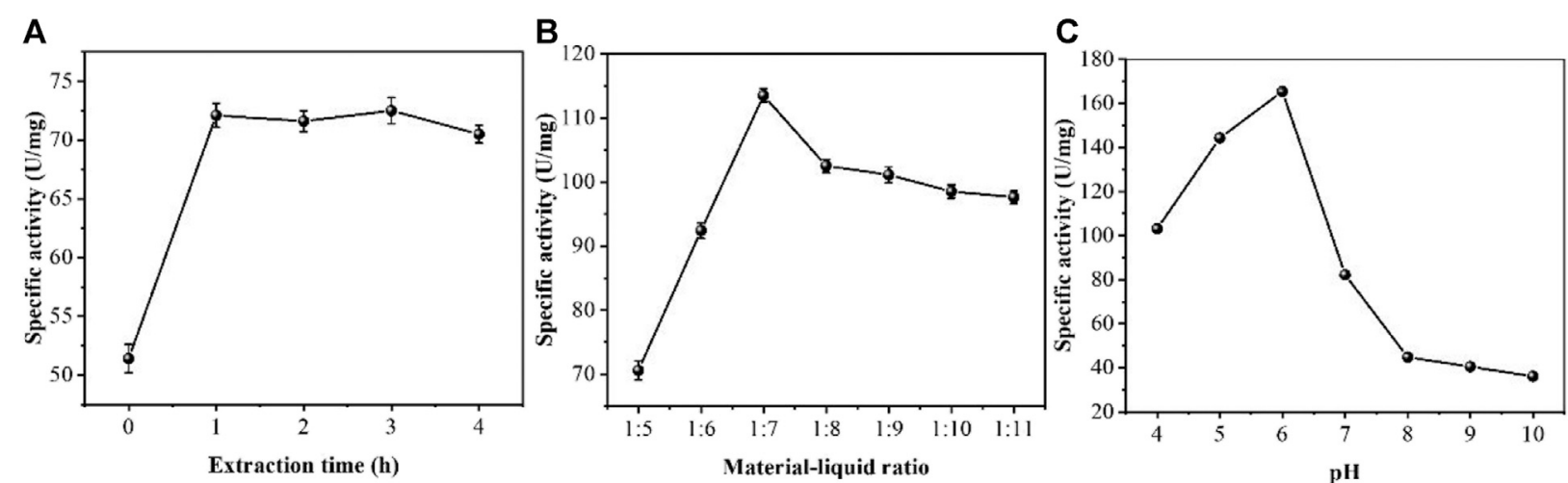

FIGURE 1 | Effect of (A) extraction time (B) material-liquid ratio and (C) pH on enzyme specific activity of Erycibe obtusifolia.

Peroxidases can largely reflect the characteristics of plant growth and development, biometabolic status, ability to adapt to the external environment and genetic differences among varieties. The electrophoretic profiles of peroxidases are relatively stable under certain conditions and are as species-specific as morphological trait indicators (Yang et al., 2020; Ying et al., 2020; Zheng et al., 2020). It has been widely used as a genetic marker in plant variety identification, genetic diversity analysis, plant disease resistance analysis, plant growth and development analysis (Karimi-Maleh et al., 2020).

Non-denaturing discontinuous polyacrylamide gel electrophoresis (native PAGE) does not easily denature proteins. It essentially does not disrupt the natural conformation of proteins and the subunit interactions, so it maintains protein biological activity (Rajhans et al., 2020; Almaz et al., 2021). This method is most widely used in the detection of plant peroxidases because it does not denature proteins. Sodium dodecyl-sulfate-gelatin-poly-acrylamide gel electrophoresis (G-PAGE) is an electrophoretic technique established in the early 1980s, which is a kind of electrophoresis that maintains the enzyme biological activity after electrophoresis (Liu et al., 2020). In phycological studies, peroxidases are species-specific. Differences in peroxidases can objectively reflect the genetics among species. The use of peroxidase to assist in species identification is a relatively simple and effective. Studies have shown that peroxidases are involved in the physiological responses of plants to disease, insect, salt, and drought resistance as well as resistance to biotic stresses (Jamali et al., 2014; Baghizadeh et al., 2015; Karaman, 2021; Karaman et al., 2021).

Recently, an electrochemical-based detection technique has been developed for the study of peroxidase activity in plants (Fu et al., 2021). Since peroxidase can catalyze hydrogen peroxide accordingly, differences in catalytic activity can be used to reflect differences in peroxidase content in plant tissues. This method can potentially be used for the determination of plant sex. Electrochemical detection is a low-cost and university-based analytical technique that is particularly suitable for rapid detection. Therefore, this technology has a bright future in plant detection. There is a very large market for herbal medicine in Asia. Authentication of herbal medicines has been a problem in this market. Based on the above information, the identification of herbal medicines by using the difference of peroxidase is a direction worth exploring.

In this work, twelve herbs were selected for electrochemical testing. The peroxidases in the herbs were first extracted. Graphene-modified electrodes were subsequently used to detect these extracts in the presence of hydrogen peroxide. The results revealed a large variation of peroxidase in different herbs. This technique can potentially be used for the identification of herbal species as well as the control of herbal quality.

\section{EXPERIMENTS}

\section{Materials}

Ratan of Erycibe obtusifolia, leaf of Panax ginseng C. A. Mey, leaf of Murraya exotica L., rhizome of Zingiber officinale Rosc, seed of Cassia obtusifolia L., rhizome of Pinellia ternate (Thunb.) Breit, rhizome of Imperata cylindrica Beauv. var.major (Nees) C.E.Hubb, pericarp of Zanthoxylum bungeanum Maxim, seed of Trichosanthes rosthornii Harms, pericarp of Benincasa hispida (Thunb.) Cogn, rhizome of Semiaquilegia adozoides (DC.) Makino and seed of Strychnos nuxvomica L. were purchased from local pharmacy and identified by Nanjing University of Chinese Medicine. Disodium hydrogen phosphate, sodium dihydrogen phosphate, potassium dihydrogen phosphate, guaiacol, hydrogen peroxide, graphene ink, sulfuric acid, phosphoric acid, anhydrous ethanol, Thomas Brilliant Blue G250 , bovine serum albumin were all analytically grade.

\section{Peroxidase Extraction}

Weigh a certain amount of herbs and add PBS at $4^{\circ} \mathrm{C}$. The pulping time was $60^{\circ} \mathrm{s}$, and then extracted for a certain time at $4^{\circ} \mathrm{C}$. The filtered filtrate was frozen and centrifuged at $9,000^{\circ} \mathrm{r} / \mathrm{min}$ for $15^{\circ} \mathrm{min}$, and the supernatant was collected as the crude enzyme solution. 

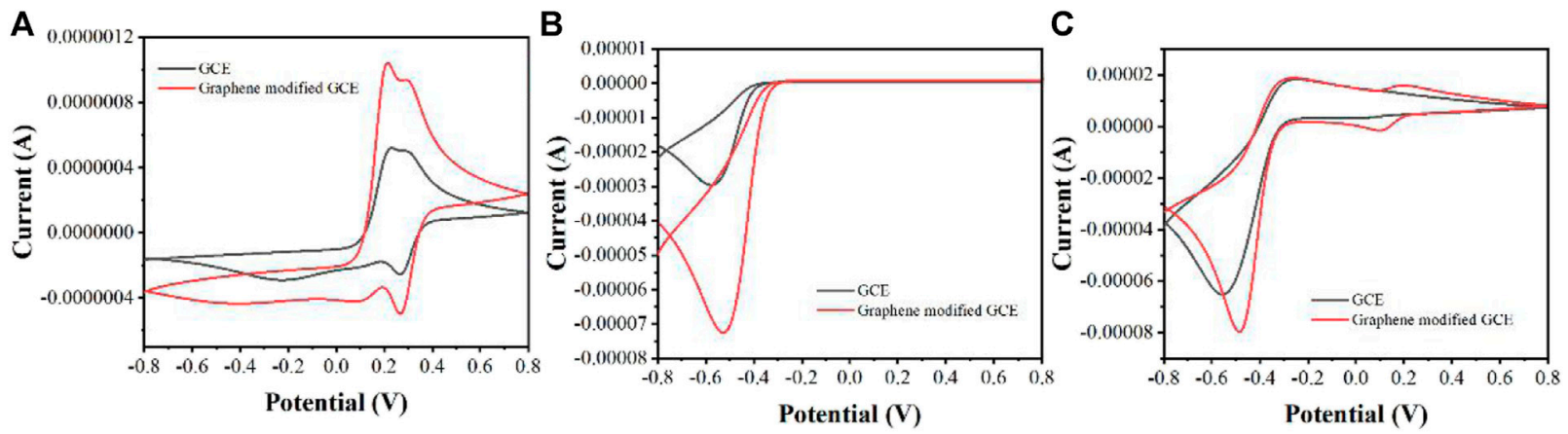

FIGURE 2 | (A) CVs of GCE and graphene modified GCE on Erycibe obtusifolia peroxidase extracts in the absence of $\mathrm{H}_{2} \mathrm{O}_{2}$ (B) $\mathrm{CV}$ s of GCE and graphene modified GCE toward $1 \mathrm{mM} \mathrm{H}_{2} \mathrm{O}_{2}$ (C) CVs of GCE and graphene modified GCE on Erycibe obtusifolia peroxidase extracts in the presence of $1 \mathrm{mM} \mathrm{H}_{2} \mathrm{O}_{2}$.

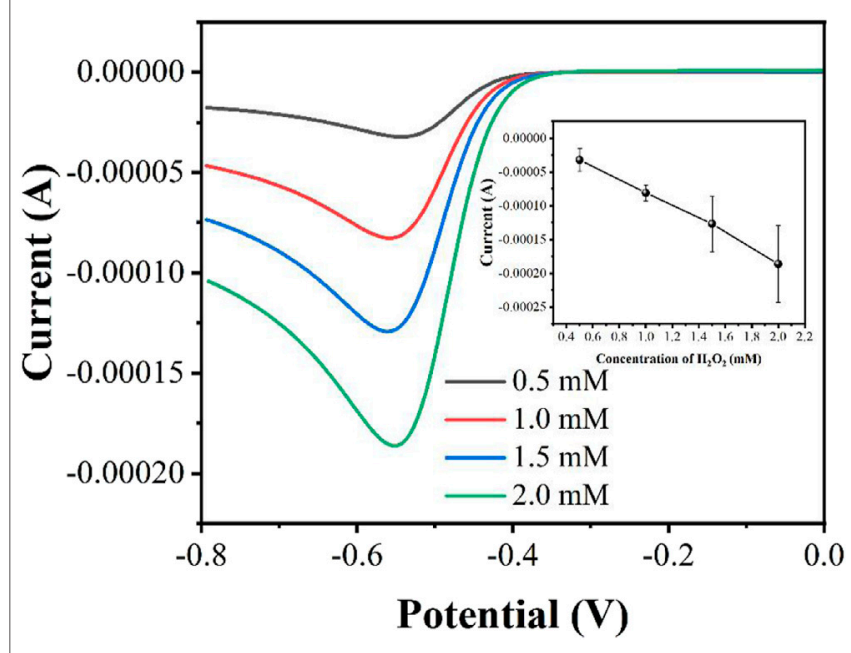

FIGURE 3 | Effect of the $\mathrm{H}_{2} \mathrm{O}_{2}$ concentration on the determination performance $(n=3)$.

\section{Enzyme Activity Measurement Based on Colorimetric Assay}

Guaiacol was used as the reaction substrate in the colorimetric assay. The reaction system consisted of $2.95 \mathrm{ml}$ of $18 \mathrm{mM}$ guaiacol and $1 \mathrm{mM} \mathrm{H}_{2} \mathrm{O}_{2}$ ( $\mathrm{pH} 5 \mathrm{PBS}$ ). Add $0.05 \mathrm{ml}$ of the enzyme solution, cover the cuvette with a lid and mix rapidly, measure the absorbance value at $470 \mathrm{~nm}$ at $30^{\circ} \mathrm{C}$, count one time every $10^{\circ} \mathrm{s}$, and use 0.01 change in absorbance value per minute as 1 unit of enzyme activity.

\section{Determination of Protein Content}

The protein content was determined by the colorimetric method of Bradford's Komas Brilliant Blue G-250. Bovine serum protein was used to make the standard curve. The absorbance value at $595 \mathrm{~nm}$ was used as the vertical coordinate for the standard curve. The standard curve was plotted with the standard protein content as the horizontal coordinate, and the protein mass in the sample was calculated by the curve equation. Specific activity is the activity per unit mass of enzyme, expressed as $\mathrm{U} / \mathrm{mg}$, specific activity = activity $(\mathrm{U}) /$ mass of protein $(\mathrm{mg})$.

\section{Enzyme Activity Measurement Based on Electrochemical Method}

All electrochemical measurements were performed using a $\mathrm{CHI}$ $820 \mathrm{D}$ electrochemical workstation with a three-electrode system. Specifically, a reference electrode $(\mathrm{Ag} / \mathrm{AgCl})$, a counter electrode (Pt foil) and a working electrode (glassy carbon electrode, GCE). Graphene ink $(0.5 \mathrm{mg} / \mathrm{ml})$ was firstly drop coated on the GCE surface and dried naturally. Then, a linear sweep voltammetry was used for detecting the electrocatalytic of peroxidase toward $\mathrm{H}_{2} \mathrm{O}_{2}$.

\section{RESULTS AND DISCUSSION}

Firstly, we optimized the extraction process of peroxidase. The extraction conditions were optimized using an orthogonal test. The results of the single-factor test were analyzed in an orthogonal test to derive the key factors influencing the peroxidase extraction of Erycibe obtusifolia. The effects of different extraction times of $0,1,2,3$ and $4 \mathrm{~h}$ on the specific activity of Erycibe obtusifolia peroxidase were investigated by fixing the material-liquid ratio $1: 5$ at $\mathrm{pH}$ 4. It can be seen from Figure $1 \mathrm{~A}$ that the enzyme specific activity increased with the increase of extraction time and stabilized when the extraction time exceeded $1 \mathrm{~h}$. The reason may be that the enzyme in Erycibe obtusifolia tissue was not fully solubilized when the extraction time was less than $1 \mathrm{~h}$. With the increase of time, the enzyme leaching gradually reached the equilibrium, and the enzyme specific activity tended to stabilize. $3 \mathrm{~h}$ later, the enzyme specific activity slightly decreased, which might be due to the inactivation of the leached enzyme in the solution environment. Figure 1B examines the effect of different stock-to-solution ratios on the specific activity of honeysuckle peroxidase. The peroxidase specific activity increased with the increase of the material-liquid ratio between 1:7 and 1:5. When the material-liquid ratio was less than 1:7, the peroxidase specific activity showed a decreasing 

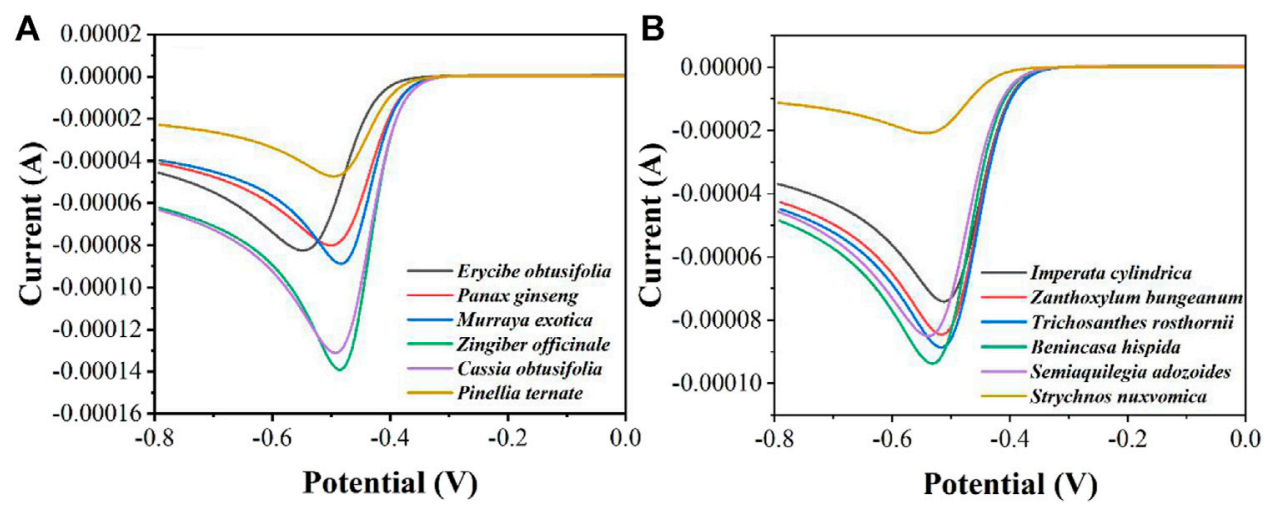

FIGURE 4 | LSV curves of (A) Erycibe obtusifolia, Panax ginseng, Murraya exotica, Zingiber officinale, Cassia obtusifolia, Pinellia ternate and (B) Imperata cylindrica, Zanthoxylum bungeanum, Trichosanthes rosthornii, Benincasa hispida, Semiaquilegia adozoides, Strychnos nuxvomica in the presence of 1 mM $\mathrm{H}_{2} \mathrm{O}_{2}$ recorded using a graphene modified GCE.

TABLE 1 | Enzyme activity measurement of Erycibe obtusifolia, Panax ginseng, Murraya exotica, Zingiber officinale, Cassia obtusifolia, Pinellia ternate, Imperata cylindrica, Zanthoxylum bungeanum, Trichosanthes rosthornii, Benincasa hispida, Semiaquilegia adozoides and Strychnos nuxvomica based on colorimetric assay.

\section{Herb}

Erycibe obtusifolia

Murraya exotica

Cassia obtusifolia

Imperata cylindrica

Trichosanthes rosthornii

Semiaquilegia adozoides
Specific activity (U/mg)

162
174
181
149
152
167

Herb

Panax ginseng
Zingiber officinale
Pinellia ternate
Zanthoxylum bungeanum
Benincasa hispida
Strychnos nuxvomica

Specific activity (U/mg)

154
197
72
169
178
31

trend with decreasing material-liquid ratio. This may be due to the increase of solids in the extraction system and the relative lack of extraction solution due to the large material-liquid ratio. When the material-liquid ratio was smaller, the enzyme leached from plant tissues was diluted and showed a decrease in enzyme activity. Figure 1C examines the effect of different extract $\mathrm{pH}$ values on the specific activity of Erycibe obtusifolia peroxidase. From Figure 1C, it can be seen that the enzyme specific activity showed a trend of increasing and then decreasing between $\mathrm{pH}$ 4-9. The buffer $\mathrm{pH}$ of six had a better extraction effect. The reason may be that the alkaline and more acidic environment had an effect on the conformation of Erycibe obtusifolia peroxidase, which led to a change in the molecular structure of the enzyme causing a partial loss of enzyme activity. On the other hand, it may be that more heteroproteins were leached at $\mathrm{pH}$ greater than 6 , thus affecting the peroxidase extraction effect.

Figure 2 shows the CV curves of GCE and graphene modified GCE on Erycibe obtusifolia peroxidase extracts. In the absence of $\mathrm{H}_{2} \mathrm{O}_{2}$ (Figure 2A), both electrodes have some redox peaks during the anodic scan and cathodic scan. These peaks are due to the oxidation and reduction of some substances possessing electrochemical activity in Erycibe obtusifolia extracts, such as flavonoids (Cai et al., 2020), pigments (Pearce et al., 2020), carotenoids (Čižmek and Komorsky-Lovri), etc.

Figure 2B shows the CV curves of the two electrodes in PBS for $1 \mathrm{mM} \mathrm{H}_{2} \mathrm{O}_{2}$. It can be seen that both electrodes have a reduction of $\mathrm{H}_{2} \mathrm{O}_{2}$ in the cathodic scan. In contrast, the graphene-modified GCE possesses a very remarkable current signal. Therefore, graphene can significantly increase the current signal due to its excellent electrical properties (Vasseghian et al., 2021).

The same can be observed in the assay of Erycibe obtusifolia extracts (Figure 2C). It can be seen from the figure that the graphene-modified electrode possesses a very significant current signal. This amplification strategy of the current signal can greatly increase the feasibility of detecting peroxidase by electrochemistry.

The concentration of $\mathrm{H}_{2} \mathrm{O}_{2}$ affects the performance of electrocatalytic response. In general, the higher the concentration of $\mathrm{H}_{2} \mathrm{O}_{2}$ will lead a higher reduction current. However, too much $\mathrm{H}_{2} \mathrm{O}_{2}$ can rapidly deplete the peroxidase enzyme, thus leading to a large variance. Figure 3 shows the LSV curves in the presence of $0.5,1,1.5$ and $2 \mathrm{mM} \mathrm{H}_{2} \mathrm{O}_{2}$. As expected, the reduction current increases with increasing concentration of $\mathrm{H}_{2} \mathrm{O}_{2}$. However, the reproducibility of the currents becomes worse as the concentration increases. Therefore, we finally chose $1 \mathrm{mM} \mathrm{H}_{2} \mathrm{O}_{2}$ as the experimental concentration.

In order to distinguish more quickly the differences in peroxidase in different herbal extracts, we measured twelve herbs by LSV (Figure 4). It can be seen that Zingiber officinale has the highest current and Strychnos nuxvomica has the lowest current. According to the data in Figure 3, the order of peroxidase activity of the twelve herbs was Zingiber officinale $>$ Cassia obtusifolia > Benincasa hispida > Murraya exotica 
$>$ Trichosanthes rosthornii > Semiaquilegia adozoides > Zanthoxylum bungeanum $>$ Erycibe obtusifolia $>$ Panax ginseng > Imperata cylindrica > Pinellia ternate > Strychnos nuxvomica. Table 1 shows the results of 12 herbs tested by colorimetric assay. Except for Zanthoxylum bungeanum and Semiaquilegia adozoides, the order of the results is consistent with that of the electrochemical assay. Such results represent that the electrochemical detection techniques we use can be used for the identification and quality control of herbs.

\section{CONCLUSION}

Peroxidase can be used as an indicator for the identification of herbs and quality control. An electrochemical-based assay was proposed for the rapid detection of peroxidase in herbal medicines. Graphene was used to modify the electrode to achieve increased signal sensitivity. Peroxidase in herbs can catalyze the electrochemical reduction of $\mathrm{H}_{2} \mathrm{O}_{2}$, so the electrochemical reduction signal of $\mathrm{H}_{2} \mathrm{O}_{2}$ can be used as an indicator for the content of peroxidase in the samples. Based on a investigation of 12 herbs, the accuracy of this detection technique is comparable to that of colorimetric method.

\section{REFERENCES}

Almaz, Z., Oztekin, A., Abul, N., Gerni, S., Erel, D., Kocak, S. M., et al. (2021). A New Approach for Affinity-based Purification of Horseradish Peroxidase. Biotechnol. Appl. Biochem. 68, 102-113. doi:10.1002/bab.1899

Baghizadeh, A., Karimi-Maleh, H., Khoshnama, Z., Hassankhani, A., and Abbasghorbani, M. (2015). A Voltammetric Sensor for Simultaneous Determination of Vitamin C and Vitamin B6 in Food Samples Using ZrO2 Nanoparticle/Ionic Liquids Carbon Paste Electrode. Food Anal. Methods 8, 549-557. doi:10.1007/s12161-014-9926-3

Barpete, S., Gupta, P., Khawar, K. M., Özcan, S., and Kumar, S. (2020). In Vitro approaches for Shortening Generation Cycles and Faster Breeding of Low B-Noxalyl-L-A, B-diaminopropionic Acid Content of Grass Pea (Lathyrus Sativus L.). Fresenius Environ. Bull. 29, 2698-2706.

Cai, Y., Huang, W., and Wu, K. (2020). Morphology-controlled Electrochemical Sensing of Erbium- Benzenetricarboxylic Acid Frameworks for Azo Dyes and Flavonoids. Sensors Actuators B: Chem. 304, 127370. doi:10.1016/ j.snb.2019.127370

Chen, Q., Man, H., Zhu, L., Guo, Z., Wang, X., Tu, J., et al. (2020). Enhanced Plant Antioxidant Capacity and Biodegradation of Phenol by Immobilizing Peroxidase on Amphoteric Nitrogen-Doped Carbon Dots. Catal. Commun. 134, 105847. doi:10.1016/j.catcom.2019.105847

Čižmek, L., and Komorsky-Lovrić, Š. (2020). Electrochemistry as a Screening Method in Determination of Carotenoids in Crustacean Samples Used in Everyday Diet. Food Chem. 309, 125706.

Demir, Z., and Işsk, D. (2020). Using Cover Crops to Improve Soil Quality and Hazelnut Yield. Fresenius Environ. Bull. 29, 1974-1987.

Dong, Y., Jing, M., Shen, D., Wang, C., Zhang, M., Liang, D., et al. (2020). The Mirid Bug Apolygus Lucorum Deploys a Glutathione Peroxidase as a Candidate Effector to Enhance Plant Susceptibility. J. Exp. Bot. 71, 2701-2712. doi:10.1093/jxb/eraa015

Fu, L., Xie, K., Wang, A., Lyu, F., Ge, J., Zhang, L., et al. (2019). High Selective Detection of Mercury (II) Ions by Thioether Side Groups on Metal-Organic Frameworks. Analytica Chim. Acta 1081, 51-58. doi:10.1016/ j.aca.2019.06.055

Fu, L., Su, W., Chen, F., Zhao, S., Zhang, H., Karimi-Maleh, H., et al. (2021). Early Sex Determination of Ginkgo Biloba Based on the Differences in the

\section{DATA AVAILABILITY STATEMENT}

The original contributions presented in the study are included in the article/Supplementary Material, further inquiries can be directed to the corresponding authors.

\section{AUTHOR CONTRIBUTIONS}

YY and LS conceived of the study. LZ and SY supervised the development program, YY, LS, and MH conducted the materials characterization. $\mathrm{MH}$ and $\mathrm{WL}$ received and curated samples and analytical records. YY and LS wrote the manuscript. All authors read and approved of the manuscript.

\section{FUNDING}

This work was funded by Natural Science Foundation of Nanjing University of Chinese Medicine (XZR2020038), Jiangsu Youth Medical Talents Project (QNRC2016255) and The Fifth Batch of Gusu Health Personnel Training Project in Suzhou (GSWS2020085).

Electrocatalytic Performance of Extracted Peroxidase. Bioelectrochemistry 140, 107829. doi:10.1016/j.bioelechem.2021.107829

Jamali, T., Karimi-Maleh, H., and Khalilzadeh, M. A. (2014). A Novel Nanosensor Based on Pt:Co Nanoalloy Ionic Liquid Carbon Paste Electrode for Voltammetric Determination of Vitamin B9 in Food Samples. LWT - Food Sci. Technology 57, 679-685. doi:10.1016/j.lwt.2014.01.023

Karaman, C., Karaman, O., Atar, N., and Yola, M. L. (2021). Tailoring of Cobalt Phosphide Anchored Nitrogen and Sulfur Co-doped Three Dimensional Graphene Hybrid: Boosted Electrocatalytic Performance towards Hydrogen Evolution Reaction. Electrochimica Acta 380, 138262. doi:10.1016/ j.electacta.2021.138262

Karaman, C. (2021). Orange Peel Derived-Nitrogen and Sulfur Co-doped Carbon Dots: a Nano-booster for Enhancing ORR Electrocatalytic Performance of 3D Graphene Networks. Electroanalysis 33, 1356-1369. doi:10.1002/ elan.202100018

Karimi-Maleh, H., Karimi, F., Malekmohammadi, S., Zakariae, N., Esmaeili, R. Rostamnia, S., et al. (2020). An Amplified Voltammetric Sensor Based on Platinum Nanoparticle/polyoxometalate/two-Dimensional Hexagonal boron Nitride Nanosheets Composite and Ionic Liquid for Determination of N-Hydroxysuccinimide in Water Samples. J. Mol. Liquids 310, 113185. doi:10.1016/j.molliq.2020.113185

Karimi-Maleh, H., Alizadeh, M., Orooji, Y., Karimi, F., Baghayeri, M., Rouhi, J., et al. (2021a). Guanine-Based DNA Biosensor Amplified with Pt/SWCNTs Nanocomposite as Analytical Tool for Nanomolar Determination of Daunorubicin as an Anticancer Drug: A Docking/Experimental Investigation. Ind. Eng. Chem. Res. 60, 816-823. doi:10.1021/acs.iecr.0c04698

Karimi-Maleh, H., Ayati, A., Davoodi, R., Tanhaei, B., Karimi, F., Malekmohammadi, S., et al. (2021b). Recent Advances in Using of Chitosan-Based Adsorbents for Removal of Pharmaceutical Contaminants: A Review. J. Clean. Prod. 291, 125880. doi:10.1016/j.jclepro.2021.125880

Karimi-Maleh, H., Orooji, Y., Karimi, F., Alizadeh, M., Baghayeri, M., Rouhi, J., et al. (2021c). A Critical Review on the Use of Potentiometric Based Biosensors for Biomarkers Detection. Biosens. Bioelectron. 184, 113252. doi:10.1016/ j.bios.2021.113252

Kizilgeci, F., Mokhtari, N. E. P., and Hossain, A. (2020). Growth and Physiological Traits of Five Bread Wheat (Triticum aestivumL.) Genotypes Are Influenced by Different Levels of Salinity and Drought Stress. Fresenius Environ. Bull. 29, 8592-8599. 
Lazzarotto, F., Menguer, P. K., Del-Bem, L.-E., Zámocký, M., and Margis-Pinheiro, M. (2021). Ascorbate Peroxidase Neofunctionalization at the Origin of APX-R and APX-L: Evidence from Basal Archaeplastida. Antioxidants 10, 597. doi:10.3390/antiox10040597

Li, H., Liu, J.-X., Wang, Y., and Zhuang, J. (2020). The Ascorbate Peroxidase 1 Regulates Ascorbic Acid Metabolism in Fresh-Cut Leaves of tea Plant during Postharvest Storage under Light/dark Conditions. Plant Sci. 296, 110500. doi:10.1016/j.plantsci.2020.110500

Liu, R., Zhang, Y., Yao, X., Wu, Q., Wei, M., and Yan, Z. (2020). ع-Viniferin, a Promising Natural Oligostilbene, Ameliorates Hyperglycemia and Hyperlipidemia by Activating AMPK In Vivo. Food Funct. 11, 10084-10093. doi:10.1039/d0fo01932a

Moon, K. M., Kwon, E.-B., Lee, B., and Kim, C. Y. (2020). Recent Trends in Controlling the Enzymatic browning of Fruit and Vegetable Products. Molecules 25, 2754. doi:10.3390/molecules25122754

Ozbek, O., Gokdogan, O., and Baran, M. F. (2021). Investigation on Energy Use Efficiency and Greenhouse Gas Emissions (GHG) of Onion Cultivation. Fresenius Environ. Bull. 30, 1125-1133.

Özkan, A. (2020). Effect of Gold Nanoparticle Functionalized Multi-Walled Carbon Nanotubes on the Properties of Na-Bentonite Water Based Drilling Fluid. Fresenius Environ. Bull. 29, 143-151.

Paravisini, L., and Peterson, D. G. (2019). Mechanisms Non-enzymatic browning in orange Juice during Storage. Food Chem. 289, 320-327. doi:10.1016/ j.foodchem.2019.03.049

Pearce, N., Davies, E. S., and Champness, N. R. (2020). Electrochemical and Spectroelectrochemical Investigations of Perylene Peri-Tetracarbonyl Species. Dyes Pigm. 183, 108735. doi:10.1016/j.dyepig.2020.108735

Rajhans, G., Sen, S. K., Barik, A., and Raut, S. (2020). Elucidation of Fungal Dyedecolourizing Peroxidase (DyP) and Ligninolytic Enzyme Activities in Decolourization and Mineralization of Azo Dyes. J. Appl. Microbiol. 129, 1633-1643. doi:10.1111/jam.14731

Tenish, Z., Minović, J., Jednak, S., and Parežanin, M. (2021). Environmental Degradation and Economic Activites in OECD Countries. Fresenius Environ. Bull. 30, 2186-2192.
Le, V. T., Vasseghian, Y., Dragoi, E. N., Moradi, M., and Mousavi Khaneghah, A. (2021). A Review on Graphene-Based Electrochemical Sensor for Mycotoxins Detection. Food Chem. Toxicol. 148, 111931. doi:10.1016/ j.fct.2020.111931

Xu, Y., Lu, Y., Zhang, P., Wang, Y., Zheng, Y., Fu, L., et al. (2020). Infrageneric Phylogenetics Investigation of Chimonanthus Based on Electroactive Compound Profiles. Bioelectrochemistry 133, 107455. doi:10.1016/ j.bioelechem.2020.107455

Yang, R., Fan, B., Wang, S. a., Li, L., Li, Y., Li, S., et al. (2020). Electrochemical Voltammogram Recording for Identifying Varieties of Ornamental Plants. Micromachines 11, 967. doi:10.3390/mi11110967

Ying, J., Zheng, Y., Zhang, H., and Fu, L. (2020). Room Temperature Biosynthesis of Gold Nanoparticles with Lycoris Aurea Leaf Extract for the Electrochemical Determination of Aspirin. Rev. Mex. Ing. Quím. 19, 585-592. doi:10.24275/ $\mathrm{rmiq} / \mathrm{mat} 741$

Zheng, Y., Zhu, J., Fu, L., and Liu, Q. (2020). Phylogenetic Investigation of Yellow Camellias Based on Electrochemical Voltammetric Fingerprints. Int. J. Electrochem. Sci. 15, 9622-9630. doi:10.20964/2020.10.54

Zhou, J., Zheng, Y., Zhang, J., Karimi-Maleh, H., Xu, Y., Zhou, Q., et al. (2020). Characterization of the Electrochemical Profiles of Lycoris Seeds for Species Identification and Infrageneric Relationships. Anal. Lett. 53, 2517-2528. doi:10.1080/00032719.2020.1746327

Conflict of Interest: The authors declare that the research was conducted in the absence of any commercial or financial relationships that could be construed as a potential conflict of interest.

Copyright (c) 2021 Yue, Su, Hao, Li, Zeng and Yan. This is an open-access article distributed under the terms of the Creative Commons Attribution License (CC BY). The use, distribution or reproduction in other forums is permitted, provided the original author(s) and the copyright owner(s) are credited and that the original publication in this journal is cited, in accordance with accepted academic practice. No use, distribution or reproduction is permitted which does not comply with these terms. 